\title{
An efficient classified radial basis neural network for prediction of flow variables in sharp open-channel bends
}

\author{
Azadeh Gholami ${ }^{1} \cdot$ Hossein Bonakdari ${ }^{1} \cdot{\text { Amir Hossein } \text { Zaji }^{1} \cdot \text { Ali Akbar Akhtari }}^{1}$
}

Received: 24 May 2018 / Accepted: 28 June 2019 / Published online: 15 July 2019

(c) The Author(s) 2019

\begin{abstract}
In this study, a comparative analysis is done to evaluate the ability of classified radial basis function neural network (CRBFNN) model in estimation of flow variables in sharp open-channel bends with bend angles of $60^{\circ}$ and $90^{\circ}$. Accordingly, a RBFNN model is integrated with classification method to design a novel CRBFNN model to predict two velocity and flow depth parameters in a $60^{\circ}$ sharp bend. Furthermore, Gholami et al. (Neural Comput Appl 30:1-15, 2018a) pointed out to acceptable ability and more efficiency improvement of hybrid CRBFNN model in prediction of flow variables in $90^{\circ}$ sharp open-channel bend compared to simple RBF model. On the other hand, the flow pattern in sharp bends is more complicated than in mild open-channel bends. Moreover, the behavior of flow and its variables is varied in $60^{\circ}$ and $90^{\circ}$ sharp bends. Therefore, the present paper is aimed to evaluate the performance of RBF and CRBF models in two $60^{\circ}$ and $90^{\circ}$ (Gholami et al. 2018a) sharp open-channel bends. Available experimental data for velocity and flow depth at six different hydraulic conditions are used to train and test the CRBFNN and simple radial basis function neural network (RBFNN) networks in $60^{\circ}$ open-channel bend. Accordingly, efficiency of both RBFNN and CRBFNN models in different bend cross sections is evaluated and compared with each other. The results show that using classified model has improved the simple RBF model performance, as in the CRBFNN model, the error root mean square error and mean absolute error value, $18 \%$ and $15.3 \%$ for the flow depth prediction and $9 \%$ and $5 \%$ for the velocity prediction compared to the simple RBFNN model is reduced, respectively. Furthermore, the comparison of model performance in $60^{\circ}$ and $90^{\circ}$ bends represents that both RBFNN and CRBFNN models in all discharge values in velocity prediction have more ability in $60^{\circ}$ bend so that the mean absolute relative error (MARE) value in $60^{\circ}$ bend is equal to 0.080 and 0.082 which are lower than MARE values in $90^{\circ}$ bend $(0.125$ and 0.131 for RBFNN and CRBFNN, respectively). Furthermore, both RBFNN and CRBFNN models with lower MARE values equal to 0.015 and 0.012 in $90^{\circ}$ bend have more accuracy than the models in $60^{\circ}$ bend $(0.017$ and 0.014$)$. Therefore, the proposed classified models can be used in design and implementation of the curved channels with various bend angles.
\end{abstract}

Keywords Classified model $\cdot$ Radial basis function neural network $\cdot 60^{\circ}$ Bend $\cdot 90^{\circ}$ Bend $\cdot$ Flow velocity $\cdot$ Flow depth

\section{Introduction}

Flow pattern in curved paths is different from direct ones. The presence of bend in the river path and artificial channels causes the researchers to perform a lot of researches on flow structures in bends. This subject is important when it was understood that complex flow structure and high turbulence in bends cause to create phenomena such as outer wall erosion, sedimentation in inner wall, water surface slope in

Azadeh Gholami

gholamiazadeh1@gmail.com

1 Department of Civil Engineering, Razi University, Kermanshah, Iran river width or through the bend, changing of maximum flow velocity situation, bed washing in moveable beds, changing geometry plan and river path. Therefore, recognition of flow characteristics in curved channels is the favorite of most researchers. Researchers believe that the secondary flows which are created from interaction of centrifugal forces and pressure gradient (Lien et al. 1999; Ferguson et al. 2003) are the main factor to induce these phenomena (Naji et al. 2010; Shaheed 2016). In mild bends, there is more opportunity to making this interaction and the flow passes more path through the bend despite of sharp bends that flow is suddenly affected by bend therefore the flow structure and the mentioned above phenomena in sharp bends are more complex than mild bend (Ye and McCorquodale 1998). One 
of the few researches on sharp bends is related to Leschziner and Rodi 1979's study. They pointed out that the main item to transfer maximum velocity to outer wall in final bend cross section is longitudinal pressure gradient, while in mild bend the main factor is secondary flows. Experimental and numerical studies have been done on the flow patterns at different bend angles by many researchers. Jung and Yoon (2000) studied flow pattern in a $180^{\circ}$ mild bend. They observed that, generally, in mild bends with any type of bed material, maximum velocity for the first half of the entrance zone of the bend is oriented toward the inner wall, and as it moves toward the end of the bend, gradually, its geometric location falls on the outer wall. Uddin and Rahman (2012) Blanckaert and Graf (2001) evaluated the three-dimensional velocity pattern and the cause of secondary and spiral flow formation in the bends experimentally. In relation to the numerical works, De Marchis and Napoli (2006) examined the flow pattern in sharp bends using computational fluid dynamic (CFD) as three dimensions. The velocity distribution and water surface in the channel were also considered, and it was declared that at the end of the bend, the velocity value at the outer channel wall will be greater than at the rest. Ramamurthy et al. (2012) examined the flow pattern in a $90^{\circ}$ sharp bend using three-dimensional numerical model, and they indicated that using a suitable method for free surface modeling and a turbulence model that solve the heterogeneity of flow turbulence in the prediction of the secondary rotary cells (especially rotary tributary cells at outer channel wall) is very important. Moharana and Khatua (2014) analyzed flow along the meander channel. The velocity profile and water surface variations have been methodically analyzed at different cross sections. The authors stated that the water surface profile remains higher on the outer wall than at the inner wall at every channel section. The results show that velocity profile shows higher-velocity results at the inner wall than at outer wall and gradually decreases toward the outer wall and horizontal velocity profile of a highly sinuous meandering channel remains higher at the inner wall of the channel section and decreases toward the outer wall. Gholami et al. (2014) using experimental and numerical models evaluated the flow pattern in $90^{\circ}$ sharp bend and studied the velocity and flow depth changing circumstances. They concluded that in the sharp bend, unlike the mild bend, maximum velocity up to the end bend sections remains at the inner channels wall. Also, they and Bodnár and Př́hoda (2006) by using numerical study on $90^{\circ}$ sharp bend declared that transverse water surface slope in sharp bends is nonlinear despite mild bends which had linear slope according to De Vriend and Geldof (1983) and Steffler et al. (1985)'s studies. Gholami et al. (2016a) evaluated the variation of water surface levels in $120^{\circ}$ sharp bend numerically. They referred to nonlinear distribution of transverse water surface level changes so that these changes in inner half-width cross section are greater than in outer half-width of channel. They presented practical and certain relationships in calculating the water surface level differences along the bend.

The ability of soft computing methods in the analysis of the complex issues caused extensive use of these methods in various engineering sciences (Kim and Parnichkun 2017; Manu and Thalla 2017; Sanikhani et al. 2018; Li et al. 2019), especially river engineering (Ghorbani et al. 2018; Yaseen et al. 2018a, b) and water engineering such as sediment transport (Azamathulla et al. 2012; Kumar et al. 2014; Pektaş and Doğan 2015; Afan et al. 2016; Ebtehaj and Bonakdari 2017), scour (Zahiri et al. 2014; Balouchi et al. 2015; Yousif et al. 2019), hydraulic structures (Basser et al. 2014; Bonakdari and Zaji 2018), rainfall and runoff (Kisi et al. 2013; Sulaiman et al. 2018; Tao et al. 2018a, b), flood forecasting (Lohani et al. 2014; Kasiviswanathan et al. 2016; Solgi et al. 2017; Diop et al. 2018; Al Sudani et al. 2019), groundwater level (Chang et al. 2016; Li et al. 2017), stable channel designing (Bonakdari and Gholami 2016; Gholami et al. 2017a, b, c, d, 2019a, b, c). In the fields of curved channel, in recent years the authors used various types of AI methods in prediction of different flow variables in some angles $\left(60^{\circ}, 90^{\circ}\right.$ and $\left.120^{\circ}\right)$ of open-channels bends. Gholami et al. (2017b) investigated the complete flow pattern governing to $90^{\circ}$ sharp bend using adaptive neuro-fuzzy inference system (ANFIS) model based on different optimization algorithms such grid partitioning (GP) and sub-clustering (SC) methods for fuzzy inference system generation. Their results demonstrated the high ability of ANFIS in combination of back-propagation (BP) algorithm in prediction of flow variables. One of the most common soft computing methods is artificial neural networks (ANN) which applies in different types such as multi-layer perceptron (MLP), radial basis function (RBF) and so on (Wu and Wang 2012; Ghosh et al. 2015). Simple structure, high performance, high train speed caused extensive application of RBF model in different sciences (Moody and Darken 1989; Park and Sandberg 1991; Sarimveis et al. 2003; Bilhan et al. 2011; Jiang et al. 2012). Gholami et al. (2015) presented an ANN model based on MLP type in prediction of different flow variables (velocity fields, flow depth changes, streamlines, etc.) in a $90^{\circ}$ sharp bend extensively. They compared the MLP model results with a computational fluid dynamic (CFD) model and declared that MLP model is capable of estimating the flow pattern in curved channel similar to CFD model and has an acceptable performance in accordance with experimental data. They announced that despite high efficiency of MLP model, the CFD model acts more accurately than MLP in prediction of high-risk areas such as contraction and separation zones which cause deposition and erosion in outer and inner walls of curved channels. Tahershamsi et al. (2006) predicted sediment loads using two different types of neural networks (MLP and RBF). They found that the RBF model 
shows more errors than the MLP model. Zaji and Bonakdari (2014) evaluated the MLP and RBF model performance and linear and nonlinear particle swarm optimization (PSO) in discharge capacity anticipation at triangular side weirs. Their results indicated that MLP model compared to the rest of models in anticipation of this parameter shows the greatest error. So, one method that can improve the performance of ANN models is necessary. One of the methods is using decision tree in combination with various artificial intelligence (AI) models which cause the model performance improvement. Senthil Kumar et al. (2011) using different AI models: ANN, RBF, decision trees (DT) such as M5 and fuzzy logic (FL) predicted the suspended sediment concentration in the reservoir of the river. Their results indicated that M5 tree models are more accurate than other models. This model also presents decision makers with a better outlook compared with the rest of the models, and it offers engineers explicit expressions for practical uses. Other applications of hybrid model can be pointed out to rainfall-runoff model (Solomatine and Dulal 2003), flood forecasting (Solomatine and Xue 2004), scour downscaling (Goyal and Ojha 2011), rating curves modeling (Ajmera and Goyal 2012; Bhattacharya and Solomatine 2005), discharge estimation (Wolfs and Willems 2014). In the field of curved channels using these classified models, Gholami et al. (2016b, c) and Gholami et al. (2018a) presented different ANN models (MLP and RBF models) in combination with DT to improve the ability of classified ANN models compared to simple MLP and RBF models in estimation of flow variables in $90^{\circ}$ sharp bend extensively. Their results showed the high performance of hybrid DT models in comparison with simple ANN models. The DT models ability to present practical and reliable equations along with simple matrix makes these models as appropriate models in calculating flow variables in curved channels. On the other hand, because of the importance of angle of $60^{\circ}$ in deviations, convergence intakes, inlet channels and bends and because of the complicated flow nature especially in sharp bends, engineers are interested in the investigations of this angle of curved channels. In the fields of evaluation of flow pattern in $60^{\circ}$ sharp bends, based on knowledge of authors fewer recent studies have been seen. Gholami et al. (2016d) by fully numerically study based on CFD and Gholami et al. (2019d) investigated the flow patterns in $60^{\circ}$ sharp bend using ANN, CFD and support vector machines (SVM) models. Their results showed that the ANN models with high correlations in results have an acceptable performance compared to other numerical models. However, the CFD models considering physics that governs fluid flow are introduced as important numerical models that act similar to ANN model with a less difference. On the other hand, Gholami et al. (2019d) stated that the ANN model in some critical zones cannot detect the pattern governing on flow which caused the model efficiency to decrease. Accordingly, based on recent studies in $60^{\circ}$ bend, the necessity to high powerful and robust model is felt in evaluating flow pattern in $60^{\circ}$ open-channel bend. So, in order to increase the performance of previous AI models, Gholami et al. (2019e) investigated the application of hybrid ANN models integrated with classification technique. However, the main focus of Gholami et al. (2019e) is to extensively analyze the uncertainty of hybrid models regarding application of these models in studies of Gholami et al. (2018a). On the other hand, the flow pattern in sharp bends of open channels is more complicated than in mild channels bend because of sudden change of flow path. And also, flow patterns in various angles of bend $\left(30^{\circ}, 60^{\circ}, 90^{\circ}, 120^{\circ}\right.$ and $\left.180^{\circ}\right)$ are different in the sharp bends (Gholami et al. 2016a). Accordingly, performance of hybrid models in different bend angles is of great importance for engineers to use a practical and useful AI model in the design and implementation of curved channel.

Therefore, in this study, first, the radial basis function neural network model based on classification tree (CRBFNN) to improve the simple RBF model performance is modified. The classified radial basis function (CRBF) and simple RBF models predict the velocity and water surface depth parameters at $60^{\circ}$ sharp bend. The performance of both models is evaluated and compared with each other. Furthermore, another contribution of this study is investigation of the performance of CRBF and RBF models in two important bend angles of $60^{\circ}$ and $90^{\circ}$ in order to evaluate the capability of RBF and hybrid models in different bend angles. Accordingly, the results of Gholami et al.'s (2018a) study are used in estimation of velocity and flow depth in a $90^{\circ}$ sharp bend to compare with $60^{\circ}$ bend results in this study. Discharge is a key input parameter in network training so that 6 different discharge modes are used for train and test models. The performance of simple RBF and CRBF models in different channel cross sections and different discharges is studied and compared with the errors contours.

\section{Experimental model}

This experimental work was done on a laboratorial flume in the hydraulic laboratory at Ferdowsi University of Mashhad (Akhtari et al. 2009; Gholami et al. 2014; Akhtari and Seyedashraf 2017). The geometric flume characteristics and details are as follows: a straight entrance channel of $3.6 \mathrm{~m}$ length; curved channel with the central angle of the $60^{\circ}$ bend and its central radius $\left(R_{\mathrm{c}}\right)$ equal to $60.45 \mathrm{~m}$, a sharp bend $\left(R_{\mathrm{c}} / b=1.5<3\right)$ in terms of channel width $(b=40.3 \mathrm{~cm})$ and a straight exit channel of $1.8 \mathrm{~m}$ length. The channel's cross section is $40.3 \times 40.3 \mathrm{~cm}$ (width and height) square. The channel bed and walls are fixed and smooth and made of Plexiglas. Experiments were conducted with 6 different 
discharge flow rates of 5, 7.8, 13.6, 19.1, 25.3 and $30.8 \mathrm{l} / \mathrm{s}$. Six various hydraulic properties used in the experiments are given in Table 1. A one-dimensional velocity meter (propeller) with $2 \mathrm{~cm} / \mathrm{s}$ accuracy and a micrometer with $0.1 \mathrm{~mm}$ accuracy were utilized to read the axial velocities and water depth in the flume, respectively. It can be referred to the Gholami et al. (2014) for more experimental details. The geometric channel characteristics and a detailed view of the laboratory flume are shown in Fig. 1. Due to the side and channel bed effect on the velocity components and to determine the flow pattern, there are 13 transverse points in channel cross section and in each point, 4 depth points with $3,6,9$ and $12 \mathrm{~cm}$ from the water surface level are chosen to measure flow parameters. Calculations in 8 different cross sections including a section before the bend $(40 \mathrm{~cm})$, two sections after the bend $(40 \mathrm{~cm}$ and $80 \mathrm{~cm})$ and seven sections in bend $\left(0^{\circ}, 10^{\circ}, 20^{\circ}, 30^{\circ}, 40^{\circ}, 50^{\circ}, 60^{\circ}\right)$ are performed. Figure 2 shows a cross section and points on it at $60^{\circ}$ sharp bend.

\section{Artificial neural network methods}

The first part of this section refers to the presentation of the simple RBFNN as one of the most popular AI methods that is used in many engineering problems. After that, in the second part of this section, the CRBFNN method, as an efficient combination of a classification algorithm and the RBNN method, is illustrated. Finally, in the last part of this section, the formulations of the statistical indexes that are used in order to evaluate and compare the performance of the employed methods are presented.

\section{Radial basis neural network}

Because of the simplicity and flexibility, the RBNN method (Broomhead and Lowe 1988) is frequently used in various fields of the hydraulic engineering problems (Gan et al. 2012; Zaji et al. 2015; Al-Abadi 2016). As shown in Fig. 3,
Table 1 Experimental hydraulic properties

\begin{tabular}{llllll}
\hline No. of Test & $\begin{array}{l}\text { Normal depth y } \\
(\mathrm{cm})\end{array}$ & $\begin{array}{l}\text { Discharge Q } \\
(\text { lit/s })\end{array}$ & Velocity $(\mathrm{m} / \mathrm{s})$ & $\begin{array}{l}\text { Froude number } \\
(\mathrm{Fr})\end{array}$ & $\begin{array}{l}\text { Reynolds } \\
\text { number } \\
(\mathrm{Re})\end{array}$ \\
\hline 1 & 4.5 & 5 & 0.273 & 0.42 & 12,460 \\
2 & 6 & 7.8 & 0.321 & 0.42 & 18,460 \\
3 & 9 & 13.6 & 0.374 & 0.40 & 28,940 \\
4 & 12 & 19.1 & 0.394 & 0.36 & 36,860 \\
5 & 15 & 25.3 & 0.419 & 0.34 & 44,705 \\
6 & 17.6 & 30.8 & 0.435 & 0.33 & 50,830 \\
\hline
\end{tabular}

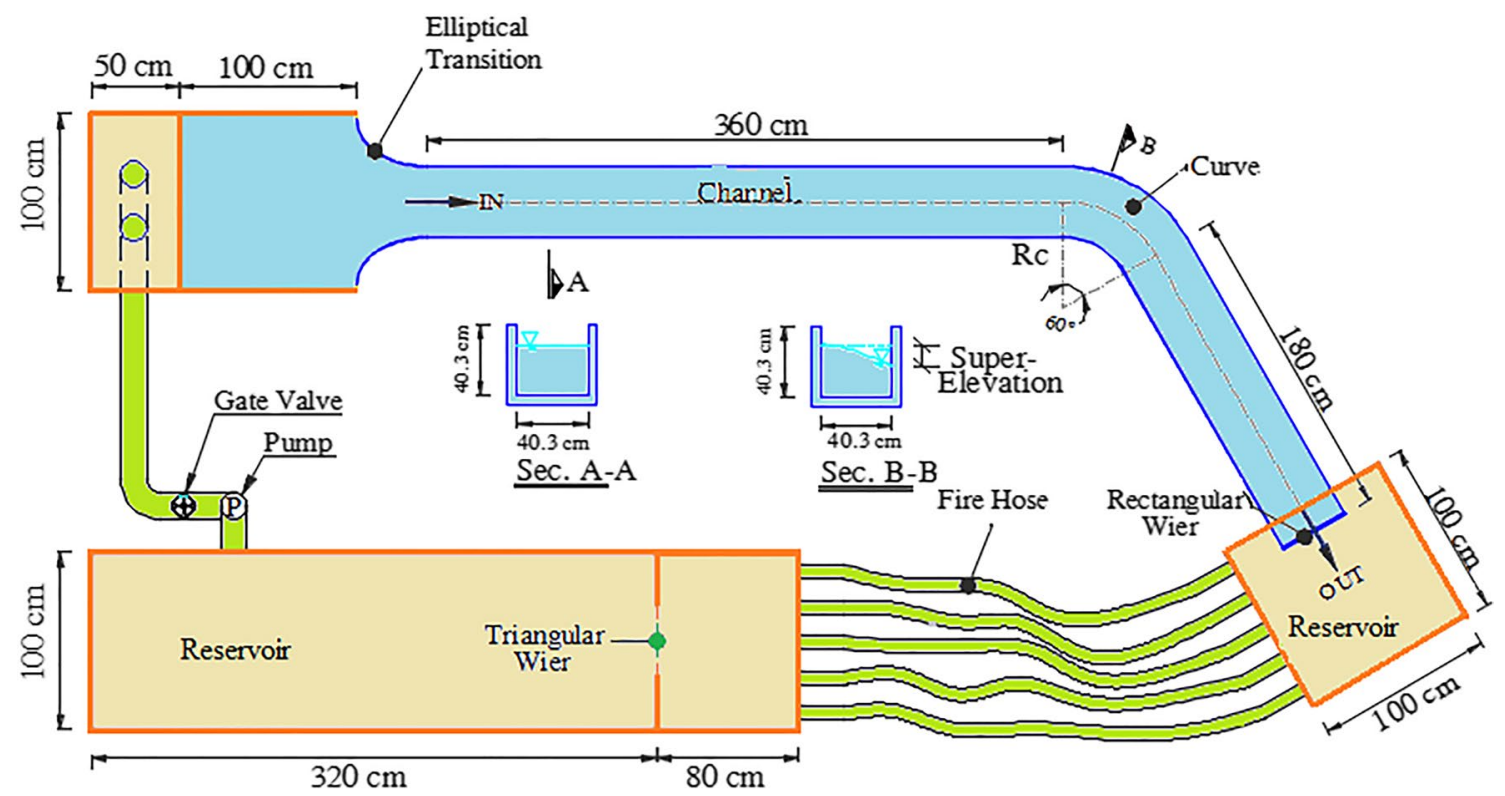

Fig. 1 Experimental model geometry and flume's details 


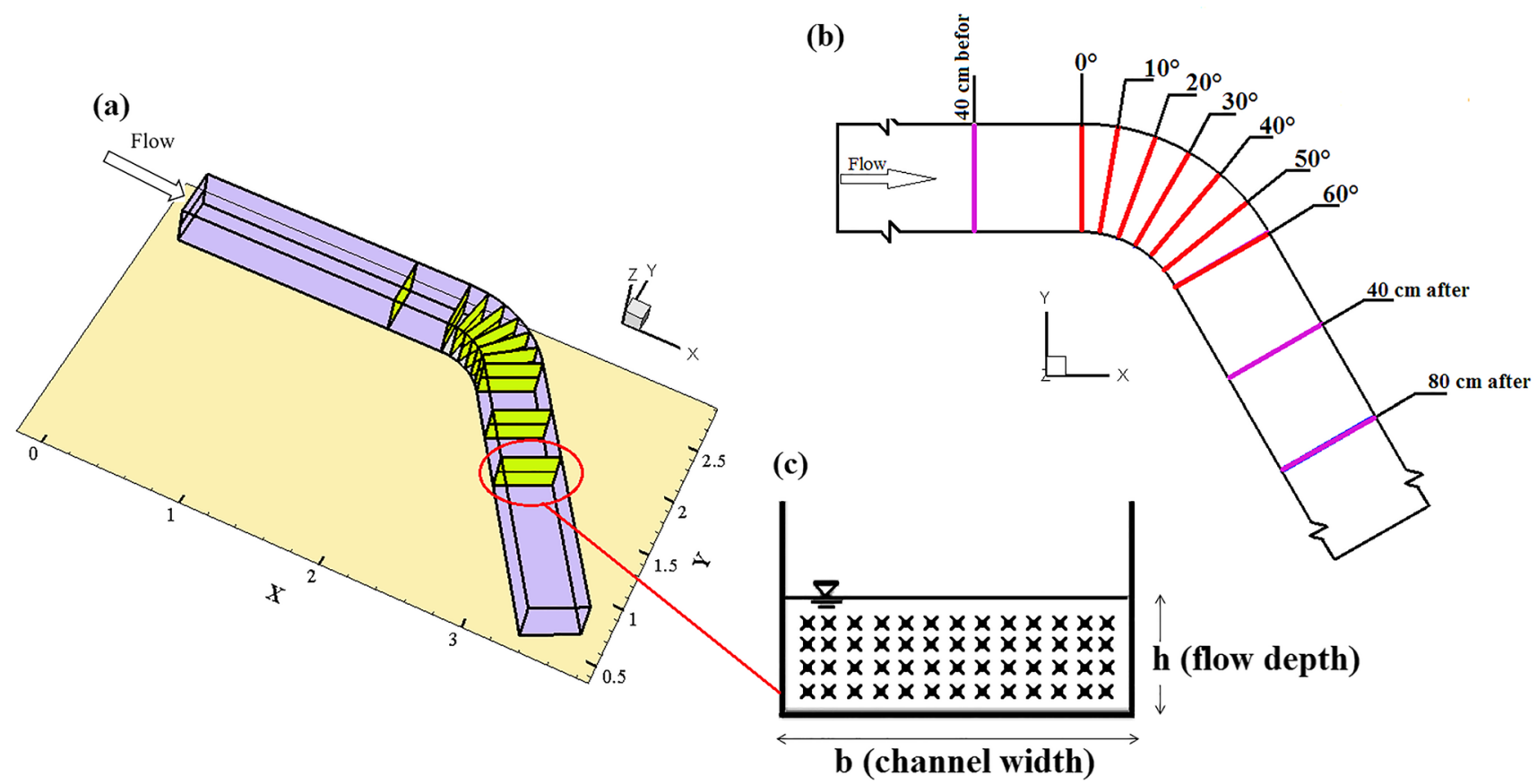

Fig. 2 a Three-dimensional view of the $60^{\circ}$ bend, $\mathbf{b}$ cross sections and $\mathbf{c}$ the section points on cross sections and their coordinates to measure the velocity and flow depth

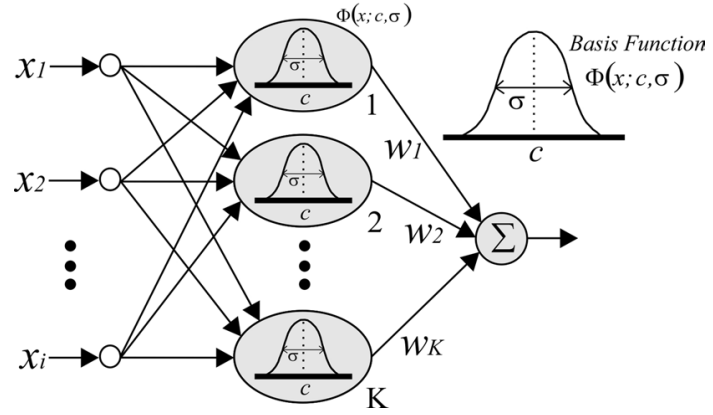

Fig. 3 The structure of a simple RBNN

the structure of an ordinary RBNN consists of three layers, namely the input, hidden and the output layers. Each of these three layers contains some neurons. The neurons of the input layer are the input variables of the considered problem so that the number of the input layer neurons is equal to the number of input variables. The neurons of the output layer perform the results of the problem. It is possible to perform various outputs from a RBNN model. However, similar to the models of the present study, in most of the researches, only one neuron is considered for the output layer. Unlike the input and the output layers, the number of hidden layer's neurons could not be determined easily and the appropriated amount of them is different for each problem.

After introducing the input variables to the RBNN model by input layer, the neurons are transferred to the hidden layer. Hidden layer could be considered as the computational core of the RBNN that collects the input neurons using the weighted summation and transfers them to the nonlinear future by radial basis functions. Radial basis $(\varphi)$ is defined as a function that only depends on the distance of the considered point from the origin ( $r$ ) (Chen et al. 2014), where $r$ is defined as follows:

$r=\|x-c\|$

In this equation, $x$ is the input variable and $c$ is the radial basis function's center. By using this nonlinear projection, the results' course of dimensionality is reduced and $\mathrm{N}$-dimensional radial basis functions are developed as follows:

$\left\{\phi\left(\left\|x-x_{i}\right\|\right) \mid i=1,2, \ldots, N\right\}$

Despite the hidden layer nonlinearity, the output layer performs similar to a linear regressor and accumulates the hidden layer's results to prepare the RBNN output as follows:

$f(x)=\sum_{i=1}^{N} c_{i} \phi\left(\left\|x-x_{i}\right\|\right)$

As mentioned above, determining the appropriated amount of hidden layer's neurons significantly depends on the considered problem so that in the present study, the trial-anderror method is employed to determine the hidden layer's neurons (Kisi 2008; Gholami et al. 2019e). 


\section{Classified radial basis neural network}

The aim of this section is to combine the RBNN as a powerful and popular regression method with a classification algorithm, namely decision tree (Coppersmith et al. 1999), to evaluate the novel hybrid method of CRBFNN (Gholami et al. 2019e). CRBFNN solves the problems more intelligently, and it is expected to perform higher simulation precision in facing with complex situations.

The reason for selecting the decision tree for the classification part of the CRBFNN is the simplicity and fastness of this algorithm. Decision tree has a class variable $Y$ that has the maximum amount of $k$. The algorithm tries to predict $Y$ considering the input variables of the problem. The decision tree training procedure starts with examining all of the input samples to find the best split position. The decision tree algorithm consists of decision nodes that are branched to other decision trees and leaf nodes. The first split point of the algorithm is called the root decision node. After finding the root decision node, the same procedure is done for each divided dataset to find the next decision node. This procedure is continued until one of the termination criteria is satisfied.

The goal of the CRBFNN method is to divide the RBNN power into $k$ parts and allocate the optimized power to each class of the dataset so that all of the RBNN power is not assigned to the whole dataset; instead, this power is partitioned and optimized to the proper positions of the dataset.

The CRBFNN method contains some important steps. In the first step, the whole dataset is divided into two training and testing datasets. After that, the training dataset is sorted from the minimum to maximum amounts of their target and divided into $k$ different parts. Then, the classification algorithm is trained according to the divided dataset. The ultimate results of the CRBFNN model are very sensible to this step because high precision of the classification algorithm leads to a big decision tree that may cause overtraining in the results. In addition, low classification precision leads to low performance of the power allocation of the RBNN so that the appropriated classification accuracy should be determined by adjusting the parameters of the decision tree algorithm that is done by the trial-and-error method. In the next step of the CRBFNN method, the trained decision tree divides the dataset into $k$ classes. Then, the primal RBNN structure is divided into $k$ smaller RBFNN models and each small RBFNN models one of the dataset's classes. Similar to the primal RBFNN model, the number of hidden layer's neurons of each smaller RBFNN model is determined using the trial-and-error method. However, in order to have a fair comparison between the ultimate results of the RBFNN and CRBFNN methods, the maximum allowable number of hidden layer's neurons of the RBNN model is considered equal to the sum of the hidden layer's neurons of the smaller RBFNN models that are used in the CRBFNN method. Finally, at the last step of CRBFNN method, the outputs of the smaller RBFNNs are cumulated and the ultimate results of the CRBFNN are exported. The CRBFNN algorithm is presented in Table 2.

After finishing the training procedure of CRBFNN method, in case of facing with a new sample, firstly, the classification part of the CRBFNN method recognizes the most appropriate class of that sample and after that, the smaller RBFNN of that specified class modeled that sample. For more details about the classified RBFNN model, Gholami et al. (2019e) can be referred.
Table 2 CRBFNN algorithm

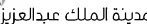
KACST

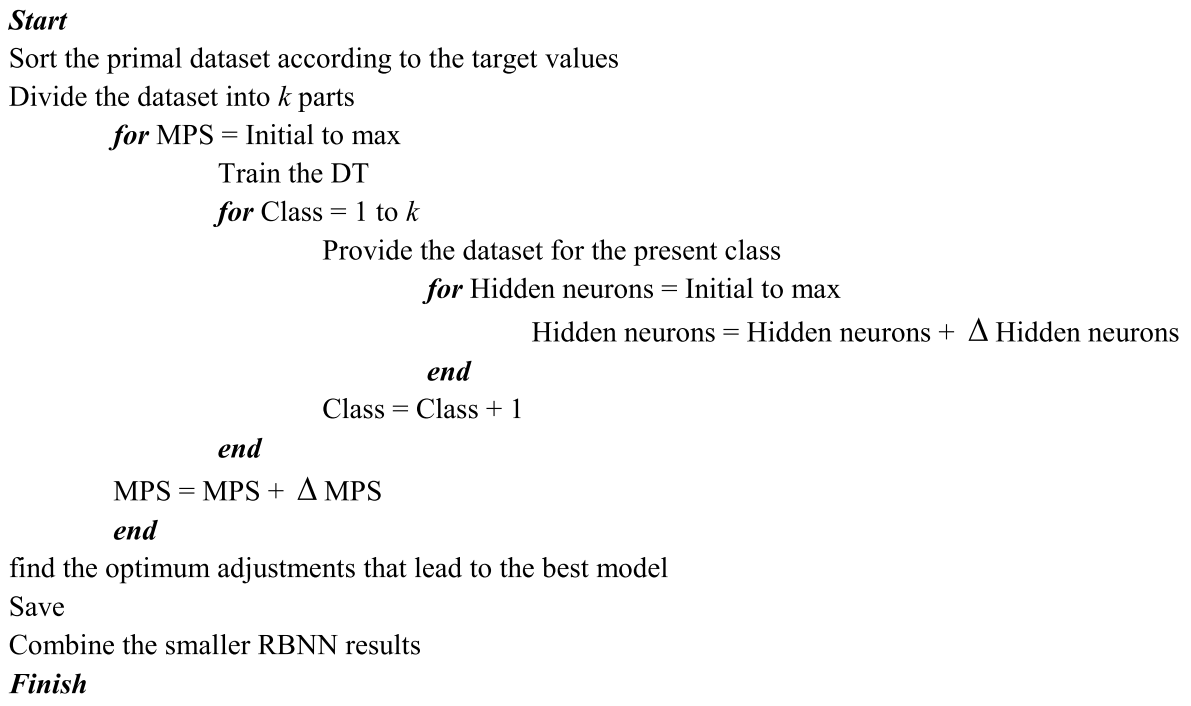




\section{Model assessment}

The results of the AI methods including RBFNN and CRBFNN are explained in this section along with the regression-based equations, the mean absolute relative error (MARE), root mean square error (RMSE), mean absolute error (MAE), determination coefficient $\left(R^{2}\right)$ and average absolute deviation $(\delta)$ statistical parameters in this paper (Khosravi et al. 2018; Yaseen et al. 2018a, b; Kisi and Yaseen 2019). These indexes are calculated as follows:

MARE $=\frac{1}{N} \sum_{i=1}^{N}\left(\frac{\left|t_{i}-O_{i}\right|}{t_{i}}\right)$

$\operatorname{RMSE}=\sqrt{\frac{\sum_{i=1}^{N}\left(O_{i}-t_{i}\right)^{2}}{N}}$

$\mathrm{MAE}=\frac{1}{N} \sum_{i=1}^{N}\left|O_{i}-t_{i}\right|$

$R^{2}=1-\frac{\sum_{i=1}^{N}\left(O_{i}-t_{i}\right)^{2}}{\sum_{i=1}^{N}\left(O_{i}-\bar{O}_{i}\right)^{2}}$

$\delta=\frac{\sum_{i=1}^{N}\left(O_{i}-t_{i}\right)^{2}}{\sum_{i=1}^{N} O_{i}} \times 100$

where $t_{i}$ is the output observational parameter, $O_{i}$ is the parameter predicted by the RBFNN and CRBFNN models, $\bar{O}_{i}$ is the mean neural models' parameter, and $N$ is the number of parameters. $R^{2}$ is the linear regression line between the predicted values by the neural network (RBFNN and CRBFNN) model and the observed values to determine the network application. MAE and RMSE are closer to zero the model performance is better also these indices have the same scale and unit of actual values.

\section{Results}

In this section, the performance of RBFNN and CRBFNN models in prediction of flow variables (velocity and flow depth) in $60^{\circ}$ sharp bend is evaluated in detail. Accordingly, to evaluate the CRBFNN model performance, a simple RBFNN model is designed. 780 experimental data for velocity and 780 data for water surface depth are used for training and testing the network. These data are related to six different discharges of 5, 7.8, 13.6, 19.1, 25.3 and $30.8 \mathrm{l} / \mathrm{s}$, of which $70 \%$ (546 data) are used to train networks and 30\% (234 data) is used to test networks.

\section{Performance evaluation of models in predicting water surface depth}

In Table 3, the performance of the hybrid model CRBFNN is compared with simple RBFNN models to predict water depth in the $60^{\circ}$ bend using different statistical indices, and from the table, it can be found that the hybrid CRBFNN model error is reduced compared to the simple RBFNN model error in three stages of train, test and whole datasets. RMSE and MAE error in the whole datasets, $17.7 \%$ and $15.3 \%$ in hybrid model, are reduced compared to the simple model, respectively. The $R^{2}$ value is almost the same in both models, indicating the high accuracy of both RBF and CRBF in predicting the water depth in the $60^{\circ}$ sharp bend.

As in this study, flow depth data of six different discharges of 5, 7.8, 13.6, 19.1, 25.3 and 30.8 1/s are used, and thus, there are corresponding different flow depths of these discharges that make the difference between performance models, and both classified and simple models have not been seen well and both show the same accuracy in prediction.

Figure 4 shows the scatter plot diagram in test dataset, and Fig. 5 represents the water depths values predicted by CRBFNN and RBFNN models in test and train datasets, respectively. Figure 4 shows that data compression in both CRBFNN and RBFNN models is around the exact line which indicates a good accuracy in models to predict the water depth in the bend. In these models, low error values in all three stages are confirmed acceptable (according to
Table 3 Evaluation of the RBFNN and CRBFNN models performance to predict the velocity in the train, test and whole datasets

\begin{tabular}{|c|c|c|c|c|c|c|c|c|c|}
\hline \multirow[t]{2}{*}{ Index } & \multicolumn{3}{|c|}{ Train datasets } & \multicolumn{3}{|c|}{ Test datasets } & \multicolumn{3}{|c|}{ Whole datasets } \\
\hline & $\mathrm{RBF}$ & CRBF & $\begin{array}{l}\text { Accuracy } \\
\text { increase } \\
(\%)\end{array}$ & RBF & CRBF & $\begin{array}{l}\text { Accuracy } \\
\text { increase } \\
(\%)\end{array}$ & $\mathrm{RBF}$ & CRBF & $\begin{array}{l}\text { Accuracy } \\
\text { increase } \\
(\%)\end{array}$ \\
\hline RMSE & 0.21 & 0.18 & 16.6 & 0.2 & 0.17 & 17.6 & 0.2 & 0.17 & 17.7 \\
\hline MAE & 0.152 & 0.13 & 17 & 0.147 & 0.126 & 16.6 & 0.15 & 0.13 & 15.3 \\
\hline$R^{2}$ & 0.99 & 0.99 & - & 0.998 & 0.998 & - & 0.998 & 0.99 & - \\
\hline BIAS & $-6.5 E-6$ & $5.8 \mathrm{E}-4$ & - & 0.0049 & -0.016 & - & 0.0015 & -0.005 & - \\
\hline
\end{tabular}


Fig. 4 Scatter plots of the RBFNN and CRBFNN models in predicting water depth with the testing datasets (a)

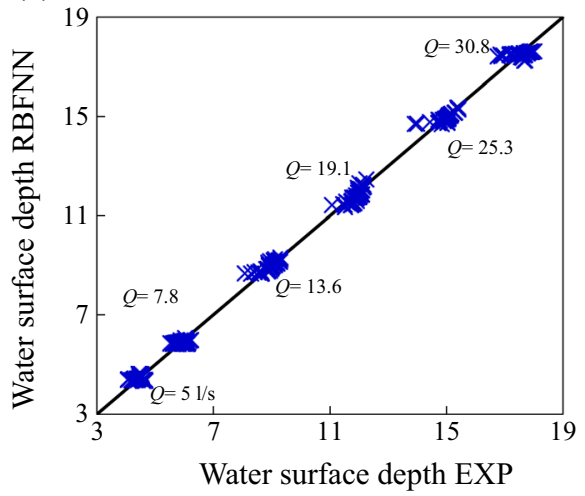

(b)

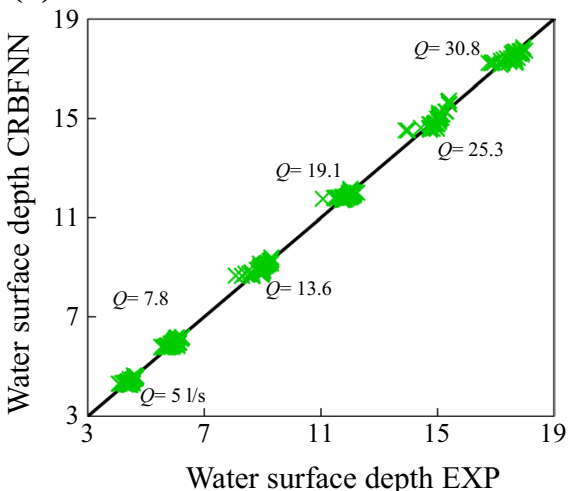

Fig. 5 Comparison of the water surface depth predicted by the RBFNN and CRBFNN models with experimental values in train and test datasets

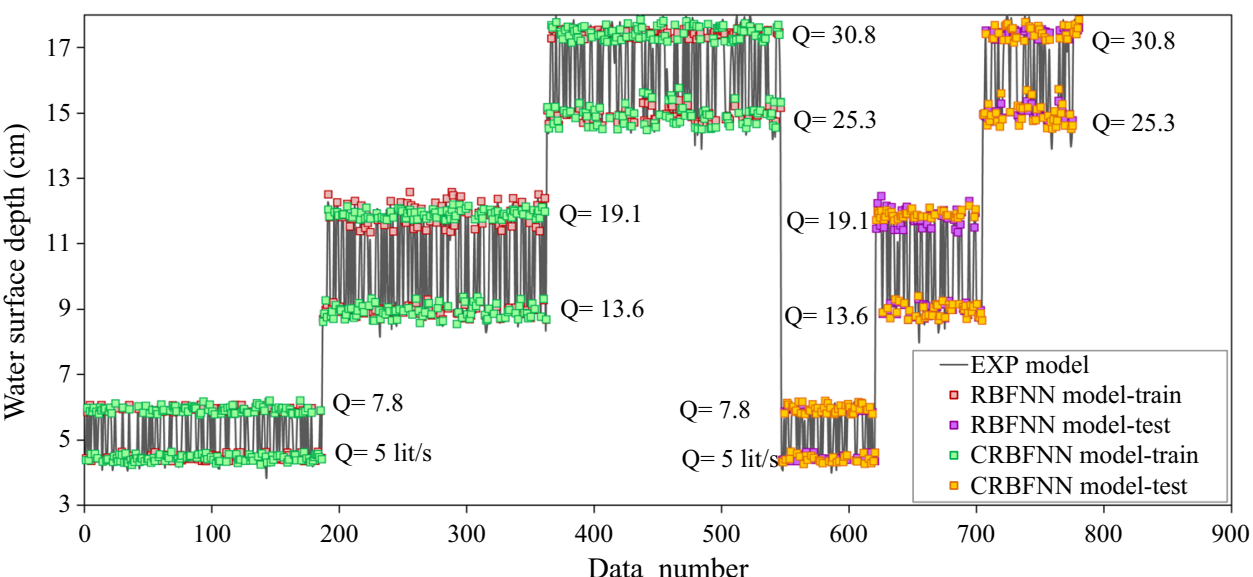

Table 3 error values). Therefore, the hybrid classified model causes improvement in simple RBFNN model performance, and CRBFNN model can be used to design sharp curved channel walls. Figure 5 shows the predicted water depth values by both models in comparison with experimental data; due to the water depth difference in each discharge, results are separated, but all are related to one model run. It is clear that both models are in good agreement with the corresponding experimental data in all discharges, but in $19.1 \mathrm{l} / \mathrm{s}$ discharge, RBFNN model at the peak shows the higher values and at the minimum points predicts the lower values than experimental values that can be seen well in both train and test datasets. At 7.8 and then 13.6 1/s discharges, both models (especially in the test dataset) completely overlap. With the increase in discharge, the data compliance is almost increased, and in the highest discharge (30.8 1/s) compared to the previous discharges, compliance will be improved. Therefore, it can be said that using hybrid classified models causes improvement of simple previous models in estimation of water surface depth, especially in high discharge values. Furthermore, the high accuracy of proposed models in predicting flow depth in high discharge values results in more usability of these models in practical cases such as design and implementation of walls of artificial curved channels.
In high values of flow depth, the flow patterns experience the more changes in variables and critical conditions which need to more accurate models to estimate flow variables. Therefore, the proposed classified models can be used in estimating flow variables with good security in the high discharge values.

\section{Performance evaluation of models in predicting flow velocity}

Figure 6 shows the velocity scatter plot in the test, and Fig. 7 demonstrates velocity values predicted by the RBFNN and CRBFNN models in test and train datasets in comparison with experimental values, respectively. Table 4 shows the RMSE, MAE, BIAS, $R^{2}$ error values for the models for velocity prediction. It can be concluded from the table that CRBFNN model accuracy is more than simple models' and $R^{2}$ values increase at all three datasets $(15 \%$ in the total dataset) so that the RMSE and MAE predicted errors in classified models have been reduced $9 \%$ and 5\%, respectively, compared to simple RBFNN model. It can be seen from Fig. 6 that the data scattering in both models (especially the CRBFNN model) is low. Also, if the fitted line is located on the left and right sides of the exact line, model experiences 
Fig. 6 Scatter plots of the RBFNN and CRBFNN models in predicting velocity with the testing datasets
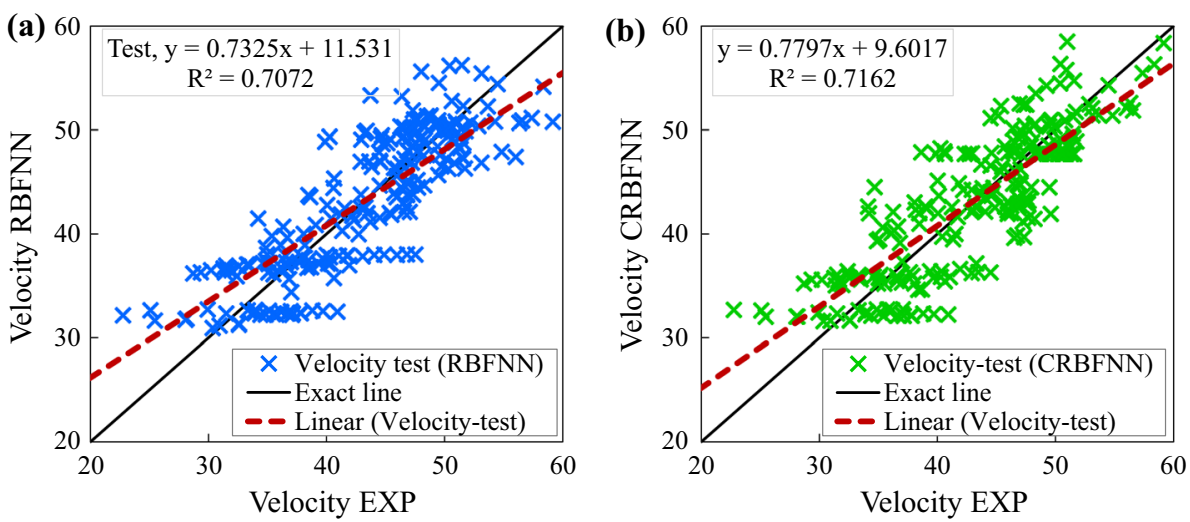

Fig. 7 Comparison of predicted velocity values by the RBFNN and CRBFNN models with experimental values in the train and test datasets

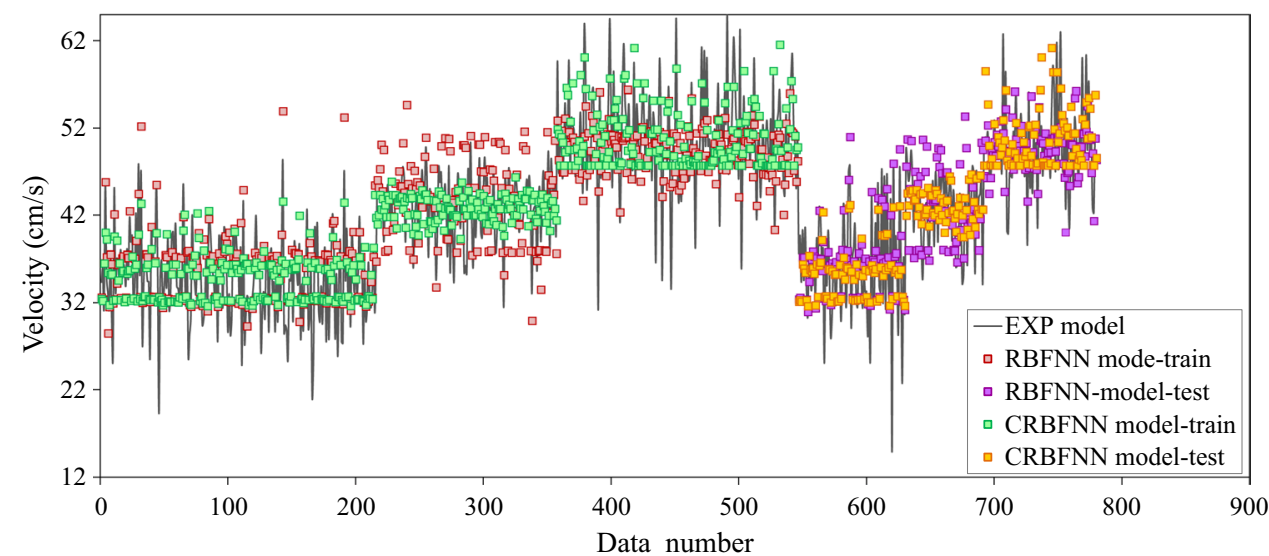

\begin{tabular}{|c|c|c|c|c|c|c|c|c|c|}
\hline \multirow[t]{2}{*}{ Index } & \multicolumn{3}{|c|}{ Train datasets } & \multicolumn{3}{|c|}{ Test datasets } & \multicolumn{3}{|c|}{ Whole datasets } \\
\hline & $\mathrm{RBF}$ & $\mathrm{CRBF}$ & Difference (\%) & $\mathrm{RBF}$ & $\mathrm{CRBF}$ & Difference (\%) & RBF & CRBF & Difference $(\%)$ \\
\hline RMSE & 6.05 & 5.6 & 8 & 4.53 & 4.2 & 8 & 4.43 & 4.08 & 9 \\
\hline$M A E$ & 6.24 & 6 & 4 & 3.5 & 3.42 & 2.3 & 3.35 & 3.2 & 5 \\
\hline$R^{2}$ & 0.63 & 0.7 & 11.2 & 0.6 & 0.71 & 18.3 & 0.61 & 0.7 & 15 \\
\hline$B I A S$ & $3 E-9$ & $E-13$ & - & -0.17 & -0.12 & - & -0.05 & -0.036 & - \\
\hline
\end{tabular}

Table 4 Evaluation of the RBFNN and CRBFNN models' performance in predicting velocity with the train, test and whole datasets the overestimation and underestimation, respectively. It is clear that both RBFNN and CRBFNN models have been considered as underestimation. RBFNN model underestimation due to more fitted line deviation from the exact line compared to the CRBFNN model is increased.

BIAS index shows the underestimation and overestimation of models, and negative and positive values of this index indicate the models as underestimation and overestimation, respectively. According to Table 4, BIAS values in the both test and whole datasets (negative BIAS values), models are considered as underestimation. This index value in the RBFNN and CRBFNN models is close to zero in three stages of datasets. In the prediction velocity models, classified model error value in the three stages is improved to the simple RBFNN model. Therefore, the classified hybrid designed model in the present study, to predict the velocity in the sharp bend channels similar to water depth prediction, is better than the simple RBFNN model and can be used in practical applications. The velocity values predicted by the models in comparison with the experimental data in Fig. 7 show that in both dataset stages (train and test), the velocity compliance predicted by the CRBFNN model with experimental values is more than by the simple RBFNN model. In the train dataset, RBFNN model at the peak and minimum points, respectively, predicts more and less values from experimental model that in the data range of 220-360 (discharge of 5,7.8, 13.6 and 19.1 1/s) can be seen better. The CRBFNN model performs well in this range. The underestimation of both models is seen in the data range of 360-540 (at the discharges of 25.3 and $30.8 \mathrm{l} / \mathrm{s}$ ) as well, and lower and 
more values are predicted in the peak and minimum point anticipation. In this range, CRBFNN model performance at the peak values is good while at minimum points RBFNN is performed better than CRBFNN. The given explanation for test can be seen also for train dataset. Therefore, it can be said that the proposed CRBFNN model in this paper can be used in prediction of high and low values of velocities which is useful to detect the risky zones exposed to erosion and sedimentation in vicinity of inner and outer banks of curved channels. Accordingly, this model can be applied in practical cases, especially design and execution of irrigation and conveyance channels such outflows in walls of curved channels.

\section{Performance evaluation of the RBFNN and CRBFNN models at different cross sections and discharges}

Table 5 shows the MAE index error value for the velocity and water depth predicted by the RBFNN and CRBFNN models in comparison with experimental values at the cross sections of $0^{\circ}, 30^{\circ}, 60^{\circ}$ and $80 \mathrm{~cm}$ after the bend on six discharges values of 5, 7.8, 13.6, 19.1, 25.3 and $30.8 \mathrm{l} / \mathrm{s}$. These results are related to one run number; in other words, discharge is an input parameter in calculation, and only the results of each discharge are separated. From the table, it is clear that in both RBFNN and CRBFNN models, the lowest error value is almost in the middle discharges (13.6 and $19.1 \mathrm{l} / \mathrm{s})$. By increasing the flow discharge at the primary sections, the error value is increased and in the end and after cross sections of bend reduced. By increasing the flow discharge in almost all sections, the error value in the CRBFNN model compared to the RBF model is reduced. But in the middle discharge (13.6 1/s) in most sections, error value in the RBFNN model is less than in classified model which with the error averaging in the two last columns is explained.

The error value averaging almost in all discharges shows that using hybrid classification algorithm reduces the error value compared to a simple model. Table (5a), related to water depth values, shows the lowest error value is obtained in the lowest flow discharges $(5 \mathrm{l} / \mathrm{s})$. By increasing the flow discharge, error value in 19.1 and $25.3 \mathrm{l} / \mathrm{s}$ discharges compared to the rest is increased. Almost in all discharges and cross sections, the error value in classified hybrid model than the simple RBFNN model is reduced. The CRBFNN model performance, in 7.8 and $13.6 \mathrm{l} / \mathrm{s}$ discharge flow with $26 \%$ and $83 \%$ reducing error, respectively, for velocity and the water depth prediction models, showed more improvement than in the rest of discharges. It can be said that using decision tree as a classification method in RBFNN structure network modification causes model improvement, especially in the water depth prediction. This model can be used in prediction of the velocity field and water depth in the curved channels for the optimal design of the channel operation.

\section{Velocity and water surface depth contours and error contours in $60^{\circ}$ bend plan by RBF and CRBF models}

Figures 8 and 9 show the velocity and water surface depth contours by the RBFNN and CRBFNN models, respectively, and below them error contours by both models in two discharges flow of 7.8 and $13.6 \mathrm{l} / \mathrm{s}$, respectively. As can be seen from Fig. 8, dimensionless velocity value $\left(v^{*}\right)$ is obtained by velocity values divided by normal velocity equal to $32.1 \mathrm{~cm} / \mathrm{s}$ related to discharge flow of $7.8 \mathrm{l} / \mathrm{s}$, and in Fig. 9, the dimensionless water depth values $\left(h^{*}\right)$ by depth values divided by the water depth in downstream of the bend
Table 5 MAE error value at RBFNN and CRBFNN models in comparison with experimental models at different cross sections in six different flow discharges in prediction of: (a) velocity and (b) water depth

\begin{tabular}{|c|c|c|c|c|c|c|c|c|c|c|}
\hline \multirow[t]{2}{*}{$\mathrm{Q}(\mathrm{lit} / \mathrm{s})$} & \multicolumn{2}{|l|}{$0^{\circ}$} & \multicolumn{2}{|l|}{$30^{\circ}$} & \multicolumn{2}{|l|}{$60^{\circ}$} & \multicolumn{2}{|c|}{$80 \mathrm{~cm}$ after bend } & \multicolumn{2}{|c|}{ Averaged } \\
\hline & $\mathrm{RBF}$ & CRBF & $\mathrm{RBF}$ & CRBF & RBF & CRBF & $\mathrm{RBF}$ & $\mathrm{CRBF}$ & RBF & $\mathrm{CRBF}$ \\
\hline \multicolumn{11}{|c|}{ (a) Velocity prediction } \\
\hline 5 & 3.1 & 3 & 4.4 & 4.4 & 2.7 & 2.76 & 4.2 & 4.07 & 3.6 & 3.5 \\
\hline 7.8 & 2.64 & 1.93 & 4.65 & 2.5 & 2.34 & 2.2 & 4.35 & 4.5 & 3.5 & 2.78 \\
\hline 13.6 & 1.52 & 2.68 & 3.83 & 2.28 & 1.94 & 2.94 & 2.22 & 4.8 & 2.37 & 3.17 \\
\hline 19.1 & 4.95 & 1.78 & 2.95 & 4.3 & 3.13 & 2.64 & 3.18 & 3.9 & 3.55 & 3.15 \\
\hline 25.3 & 2.97 & 2.86 & 3.56 & 4.3 & 2 & 2.7 & 2.17 & 2.08 & 2.7 & 2.6 \\
\hline 30.8 & 4.3 & 4.3 & 6.6 & 5.12 & 2.5 & 2.5 & 4.9 & 3.2 & 4.6 & 3.7 \\
\hline \multicolumn{11}{|c|}{ (b) Water depth prediction } \\
\hline 5 & 0.12 & 0.08 & 0.1 & 0.09 & 0.08 & 0.04 & 0.12 & 0.11 & 0.105 & 0.08 \\
\hline 7.8 & 0.075 & 0.08 & 0.13 & 0.17 & 0.14 & 0.08 & 0.13 & 0.08 & 0.12 & 0.1 \\
\hline 13.6 & 0.19 & 0.04 & 0.15 & 0.14 & 0.18 & 0.09 & 0.14 & 0.09 & 0.165 & 0.09 \\
\hline 19.1 & 0.12 & 0.21 & 0.16 & 0.12 & 0.16 & 0.15 & 0.19 & 0.11 & 0.16 & 0.15 \\
\hline 25.3 & 0.16 & 0.11 & 0.18 & 0.17 & 0.22 & 0.18 & 0.13 & 0.18 & 0.17 & 0.16 \\
\hline 30.8 & 0.13 & 0.12 & 0.15 & 0.11 & 0.15 & 0.14 & 0.09 & 0.09 & 0.13 & 0.11 \\
\hline
\end{tabular}


(a)
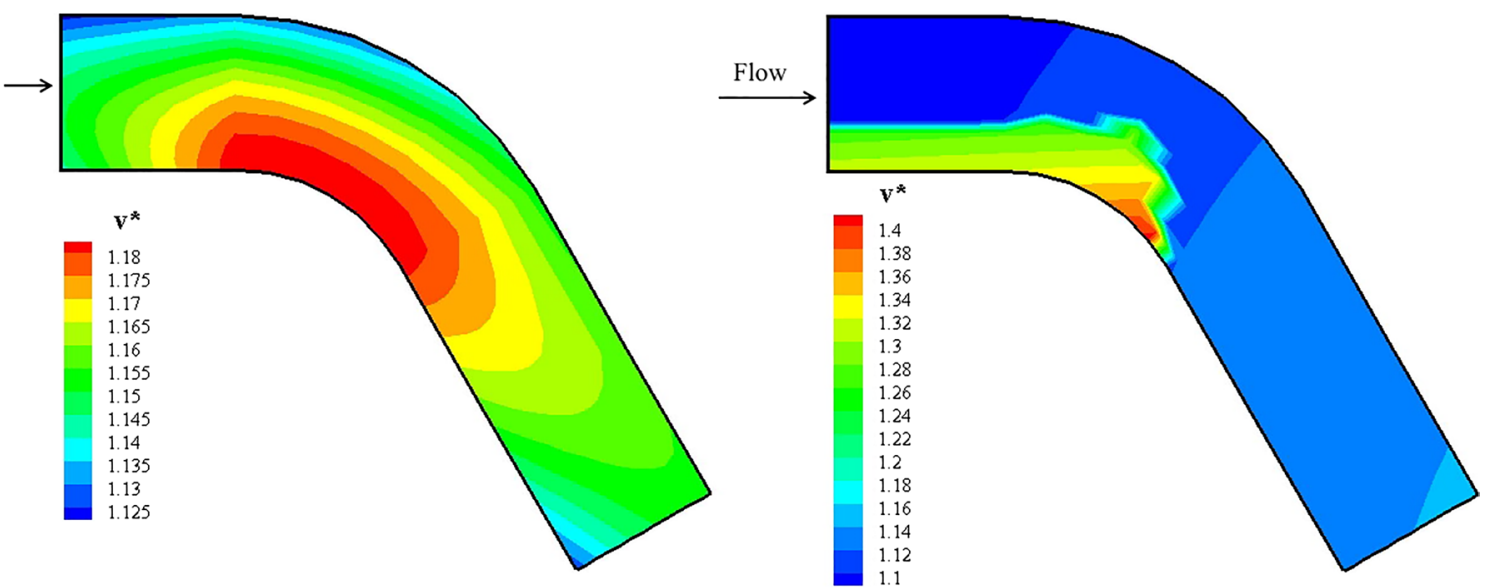

(b)
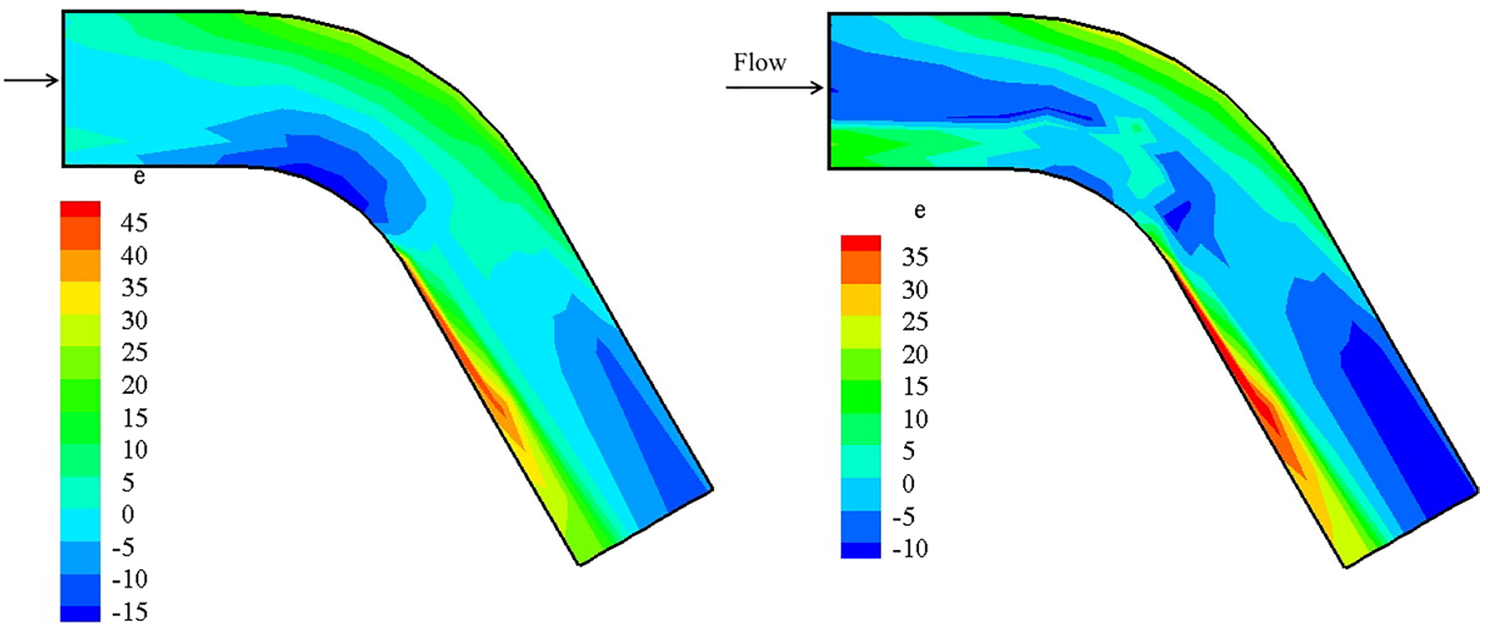

Fig. 8 a Dimensionless velocity contours at discharge of $7.81 / \mathrm{s}$ and $\mathbf{b}$ velocities error contours as $E=\left(v_{\bmod e l s}-v_{\exp }\right) / v_{\exp }$ (in percent) between the two RBFNN (left plots) and CRBFNN (right plots) models and experimental values

value equal to $9 \mathrm{~cm}$ in flow discharge of $13.6 \mathrm{l} / \mathrm{s}$ become dimensionless.

In the velocity contour from Fig. 8a, it is observed that contraction zones (areas with low velocity and faced to sedimentation) in outer bend bank get greater and separation zones (areas with high velocity and faced to erosion) in inner bank get smaller. It can be said that hybrid classified algorithm can reduce the damaging effects of the bend and scour hole will be small at inner bank. But in general, the velocity values in classified model are predicted more than in simple RBFNN model. Compared with experimental data, error contours below the chart show that in CRBFNN model error ranges ( -10 to $35 \%$ ) are less than the error ranges in the RBF model ( -15 to $45 \%$ ). It can be seen from both models that the error values in separation zones are less than in the contraction zone; the model values are in agreement with experimental values in these areas and perform well in this sensitive area. Also in the classified model, blue areas (areas with fewer errors) compared to the simple RBFNN model (especially in sections before and after the bend) is increased. Using DT classification algorithm to reduce the bending effects (the secondary flow presence in the area after the bend) is very effective and can improve the simple model performance in this area.

In the water depth contours (Fig. 9), the top row indicates the dimensionless water depth that in both models at outer wall the water surface depth values are more and less in the outer and inner walls, respectively. This is due to that in bends, with flow entrance to bend, centrifugal force and lateral pressure gradient cause the water depth in the inner and outer channel walls to decrease and increase, respectively. This matter causes a lateral gradient in the water surface; thus, the walls height designing in the curved channels is important. It can be seen from the figure that in the same 
(a)
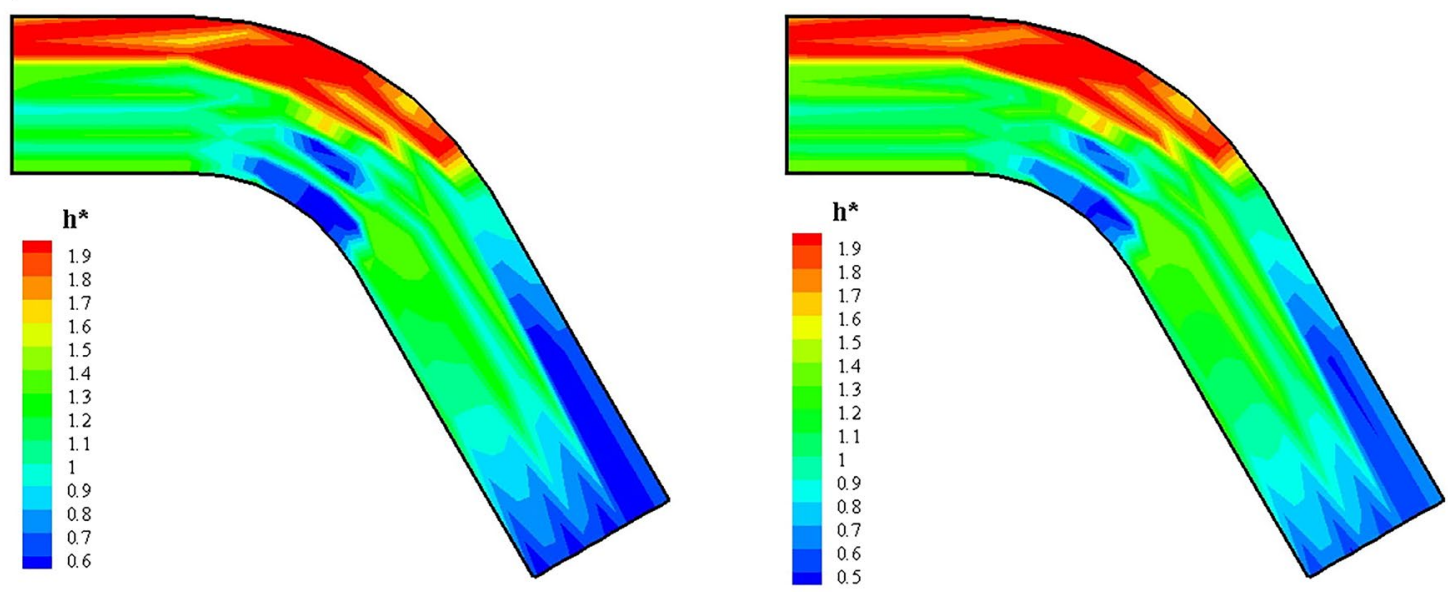

(b)
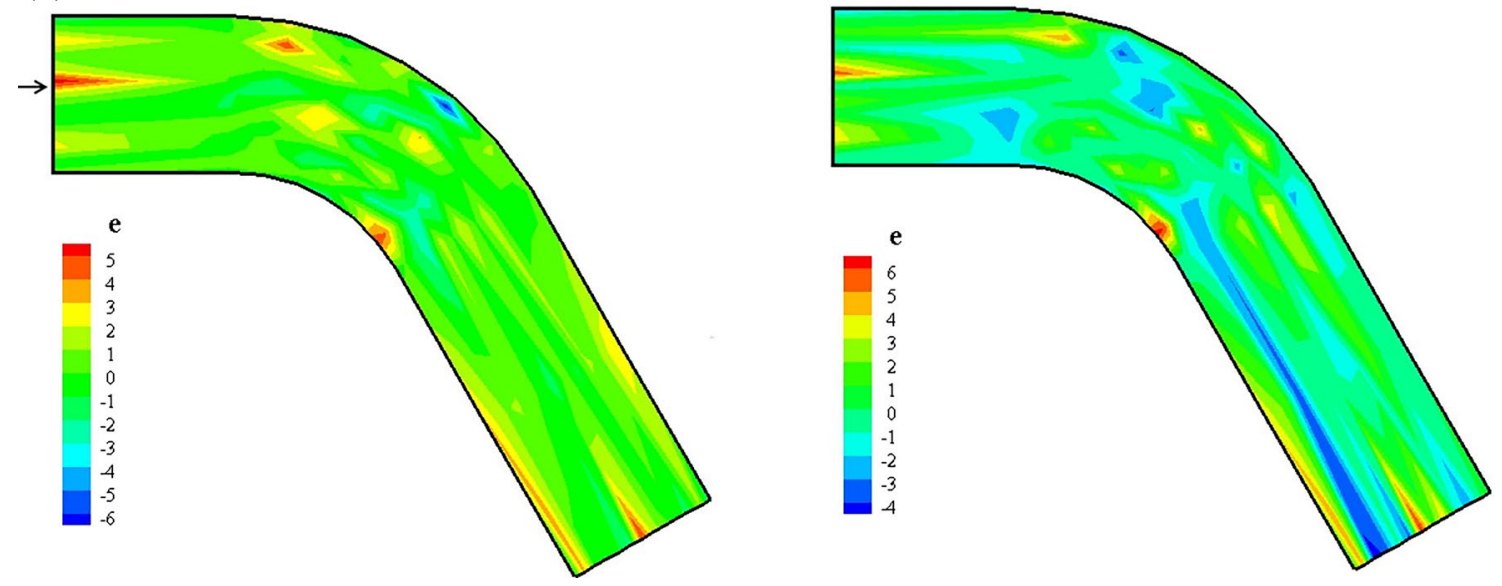

Fig. 9 a Dimensionless water depth contours at discharge of $13.6 \mathrm{l} / \mathrm{s}$ and $\mathbf{b}$ water depth error contours as $E=\left(v_{\bmod e l s}-v_{\exp }\right) / v_{\exp }$ (in percent) between the two RBFNN (left plots) and CRBFNN (right plots) models and experimental values

areas, classified model than the simple model predicts more values. From the water depth contours, error can be seen that the hybrid classified model reduced the error and blue areas are increased compared to a simple RBFNN model. Therefore, it can be said that the proposed classified CRBFNN model is more accurate than simple RBFNN model to estimate flow variables, especially in critical zones and flow depth in curved channels walls. So, these models can be used in practical cases as an alternative to simple RBFNN models.

\section{Discussion}

In this section, the performance of RBFNN and CRBFNN in $60^{\circ}$ bend design in this paper is compared with results of $90^{\circ}$ bend of Gholami et al.'s (2018a) study. The main goal of presenting this section is evaluation of performance of classified models in bends with different angles. Accordingly, Fig. 10 presents the scatter plots of RBFNN and CRBFNN models in prediction of flow velocity in $60^{\circ}$ and $90^{\circ}$ bends in all discharge values. Furthermore, the lines fitted on these data sets and also exact lines regarding each graph are drawn. Moreover, the error index values of MARE and RMSE for $60^{\circ}$ and $90^{\circ}$ bends for each discharge value separately and also for all datasets are gathered. As carefully seen in Fig. 10, in both RBFNN and CRBFNN models, the compaction of datasets around exact line in $60^{\circ}$ bend is more than in $90^{\circ}$ bend representing the more precision of both models of RBFNN and CRBFNN in prediction of flow velocity in $60^{\circ}$ bend. Furthermore, as seen in Fig. 10, the trend lines fitted in $60^{\circ}$ bend are more close to exact line than fitted trend line in $90^{\circ}$ bend so that the fitted trend line in $90^{\circ}$ bend is close to horizontal line representing the lower correlation of predicted values with corresponding experimental values. This issue is illustrated in Table 6, the 
(a)

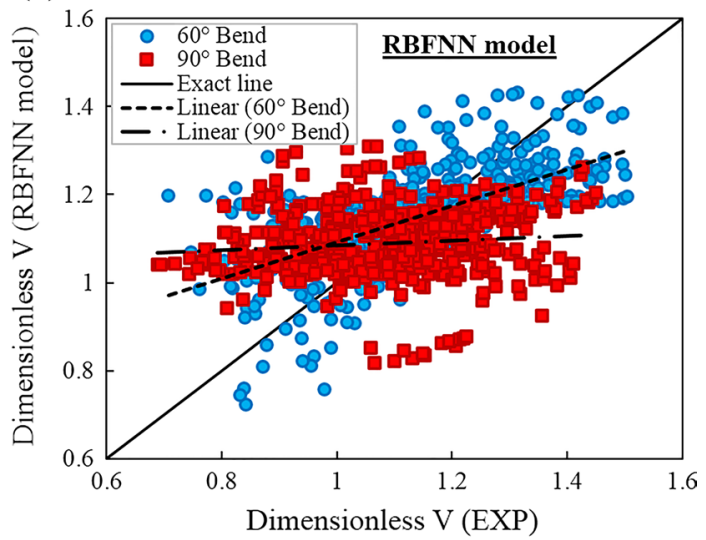

(b)

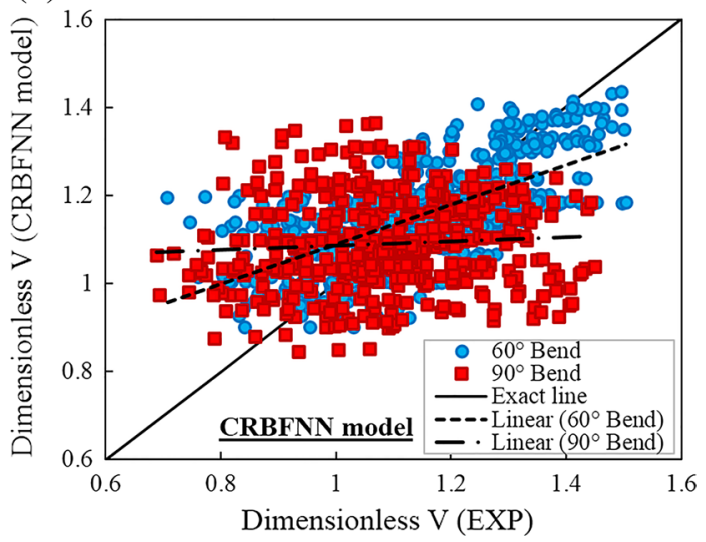

Fig. 10 Scatter plots of $\mathbf{a}$ RBFNN and $\mathbf{b}$ CRBFNN models in velocity prediction in $60^{\circ}$ and $90^{\circ}$ bends

Table 6 Index values of MARE and RMSE of RBFNN and CRBFNN models in velocity prediction in each discharge value separately and all discharges in $60^{\circ}$ and $90^{\circ}$ bends

\begin{tabular}{|c|c|c|c|c|c|}
\hline \multirow[t]{2}{*}{ Discharge } & \multirow[t]{2}{*}{ Bend } & \multicolumn{2}{|c|}{ RBFNN model } & \multicolumn{2}{|c|}{ CRBFNN model } \\
\hline & & MARE & RMSE & MARE & RMSE \\
\hline \multirow[t]{2}{*}{5} & $60^{\circ}$ & 0.113 & 4.29 & 0.116 & 4.40 \\
\hline & $90^{\circ}$ & 0.109 & 13.90 & 0.106 & 14.07 \\
\hline \multirow[t]{2}{*}{7.8} & $60^{\circ}$ & 0.096 & 4.28 & 0.086 & 3.67 \\
\hline & $90^{\circ}$ & 0.112 & 24.02 & 0.113 & 25.14 \\
\hline \multirow[t]{2}{*}{13.6} & $60^{\circ}$ & 0.062 & 3.33 & 0.070 & 3.69 \\
\hline & $90^{\circ}$ & 0.162 & 57.59 & 0.161 & 63.38 \\
\hline \multirow[t]{2}{*}{19.1} & $60^{\circ}$ & 0.070 & 3.86 & 0.064 & 3.54 \\
\hline & $90^{\circ}$ & 0.119 & 39.21 & 0.140 & 56.5 \\
\hline \multirow[t]{2}{*}{25.3} & $60^{\circ}$ & 0.062 & 3.93 & 0.074 & 4.28 \\
\hline & $90^{\circ}$ & 0.122 & 43.05 & 0.137 & 53.04 \\
\hline \multirow[t]{2}{*}{ All discharges } & $60^{\circ}$ & 0.080 & 3.95 & 0.082 & 3.93 \\
\hline & $90^{\circ}$ & 0.125 & 5.93 & 0.131 & 6.47 \\
\hline
\end{tabular}

values of RMSE and MARE in $60^{\circ}$ bend are lower than these values in $90^{\circ}$ bend. This issue is seen for both RBFNN and CRBFNN models. The more values of RMSE index in $90^{\circ}$ bend in some discharge values represent the weakness of models in prediction of high velocity values. Therefore, it can be said that in addition to lower accuracy of models in velocity prediction in $90^{\circ}$ bend, these models are weaker than $60^{\circ}$ bend in areas with high velocity values (separation zones). Figure 11 shows the variations of MARE values in $60^{\circ}$ and $90^{\circ}$ bends in prediction of velocity and flow depth in different discharge values. According to this figure, the MARE values in RBFNN and CRBFNN models in $60^{\circ}$ bend are lower than MARE values in $90^{\circ}$ bend. Therefore, it can be said that both RBFNN and CRBFNN models in all discharge values in velocity prediction have more ability in $60^{\circ}$ bend so that the MARE value in $60^{\circ}$ bend is equal to 0.080 and 0.082 which are lower than MARE values in $90^{\circ}$ bend ( 0.125 and 0.131 for RBFNN and CRBFNN, respectively).

The error index values of RBFNN and CRBFNN models in $60^{\circ}$ and $90^{\circ}$ bends in flow depth prediction are given in Table 7. As carefully seen, almost in all flow discharge values, the MARE in $60^{\circ}$ bend is more than MARE in $90^{\circ}$ bend which represents the more accuracy of models in flow depth prediction in $90^{\circ}$ bend. Furthermore, in more cases the

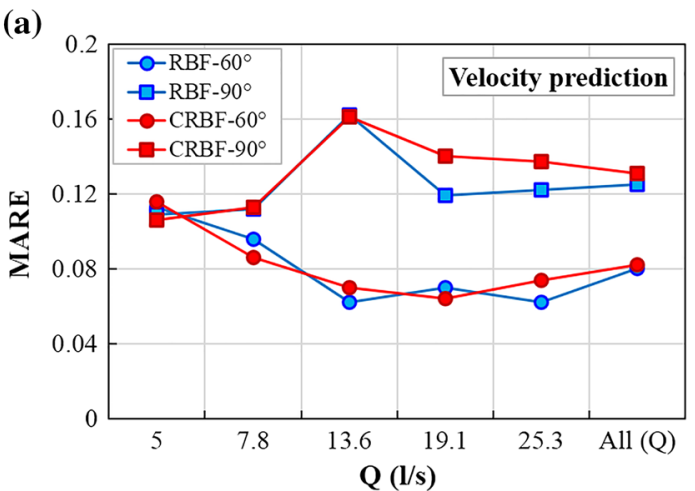

(b)

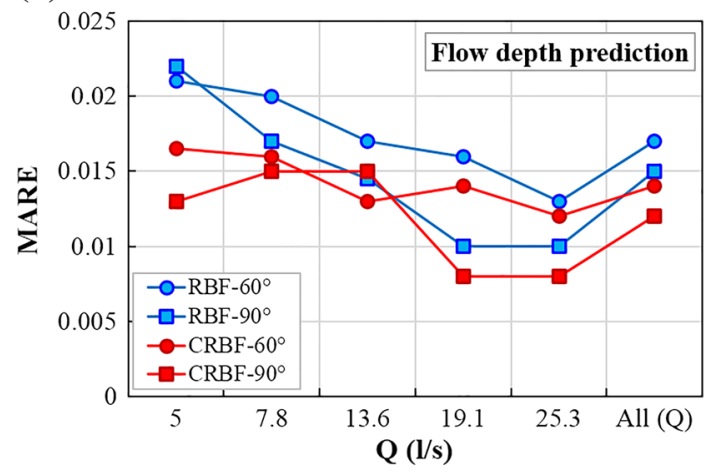

Fig. 11 Variation plots of MARE values of RBFNN and CRBFNN models in different flow discharge values separately and all discharges in predicting, a velocity and b flow depth in $60^{\circ}$ and $90^{\circ}$ bends 
Table 7 Index values of MARE and RMSE of RBFNN and CRBFNN models in flow depth prediction in each discharge value separately and all discharges in $60^{\circ}$ and $90^{\circ}$ bends

\begin{tabular}{|c|c|c|c|c|c|}
\hline \multirow[t]{2}{*}{ Discharge } & \multirow[t]{2}{*}{ Bend } & \multicolumn{2}{|c|}{ RBFNN model } & \multicolumn{2}{|c|}{ CRBFNN model } \\
\hline & & MARE & RMSE & MARE & RMSE \\
\hline \multirow[t]{2}{*}{5} & $60^{\circ}$ & 0.021 & 0.144 & 0.0165 & 0.118 \\
\hline & $90^{\circ}$ & 0.022 & 0.015 & 0.013 & 0.006 \\
\hline \multirow[t]{2}{*}{7.8} & $60^{\circ}$ & 0.020 & 0.152 & 0.016 & 0.149 \\
\hline & $90^{\circ}$ & 0.017 & 0.017 & 0.015 & 0.012 \\
\hline \multirow[t]{2}{*}{13.6} & $60^{\circ}$ & 0.017 & 0.24 & 0.013 & 0.191 \\
\hline & $90^{\circ}$ & 0.0145 & 0.026 & 0.015 & 0.027 \\
\hline \multirow[t]{2}{*}{19.1} & $60^{\circ}$ & 0.016 & 0.20 & 0.014 & 0.185 \\
\hline & $90^{\circ}$ & 0.010 & 0.024 & 0.008 & 0.014 \\
\hline \multirow[t]{2}{*}{25.3} & $60^{\circ}$ & 0.013 & 0.26 & 0.012 & 0.23 \\
\hline & $90^{\circ}$ & 0.01 & 0.046 & 0.008 & 0.024 \\
\hline \multirow[t]{2}{*}{ All discharges } & $60^{\circ}$ & 0.017 & 0.202 & 0.014 & 0.178 \\
\hline & $90^{\circ}$ & 0.015 & 0.160 & 0.012 & 0.130 \\
\hline
\end{tabular}

RMSE value in $60^{\circ}$ bend is significantly increased representing the weakness of models in prediction of high flow depth values in $60^{\circ}$ bend than in $90^{\circ}$ bend. Therefore, it can be said that both RBFNN and CRBFNN with lower MARE values equal to 0.015 and 0.012 in $90^{\circ}$ bend have more accuracy than the models in $60^{\circ}$ bend $(0.017$ and 0.014$)$. This issue is more seen in high values of discharge. Furthermore, comparison of RBFNN and CRBFNN represents that almost in all discharge values the error values in RBFNN model are more than error value in CRBFNN model representing the more accuracy of CRBFNN model than RBFNN model.

\section{Conclusion}

In this study, a RBFNN model is hybridized with classification decision tree (DT) algorithm to predict the two most important velocity and water surface depth parameters at $60^{\circ}$ sharp bend. Using hybrid classification algorithm improved the simple RBFNN model performance. Furthermore, evaluation of such models performance in different bend angles is of great importance because of variations of flow pattern which needs more cautions to design different hydraulic structures such as deviation channels, irrigation and side weirs. Accordingly, another main goal of this paper is to assess and compare the ability of RBFNN and CRBFNN in prediction of flow variables in $60^{\circ}$ and $90^{\circ}$ bends. In the velocity prediction models, CRBFNN model accuracy about $19 \%$ (with more $R^{2}$ value) compared to the simple RBFNN model is increased in the test dataset. In the water surface depth prediction model, the RMSE and MAE errors, $18 \%$ and $17 \%$, are reduced in the test dataset, respectively. The cross-section evaluation in bend demonstrates that the
CRBFNN model performance, in flow discharge of 7.8 and $13.6 \mathrm{l} / \mathrm{s}$ with $26 \%$ and $83 \%$ reduction error, respectively, for velocity and water depth prediction models show the most improvement to other rest discharges. In the separation zones of the inner bank, error value by the CRBFNN model is reduced. In entire bend, error value in CRBF model is reduced compared to the RBF model (especially in end and after the bend sections). The evaluation of models performance in $60^{\circ}$ and $90^{\circ}$ bends showed that generally simple RBFNN and CRBFNN have an acceptable accuracy in both $60^{\circ}$ and $90^{\circ}$ bends with low error values, especially in flow depth prediction. Furthermore, RBFNN and CRBFNN models act like each other and both models have more ability in $60^{\circ}$ and $90^{\circ}$ bends in velocity and flow depth prediction, respectively. Using classification decision tree algorithm in RBF structure network modification improves the model performance (especially in water depth anticipation). This model can be used to design the optimal curved channel performance and specifically exactly design the walls height of curved channel. However, prediction of flow variables in critical zones (separation and contraction) and also estimation of flow variable in flood discharge values (high discharge values) using classified CRBFNN and simple RBFNN models should be conducted with more cautions. Therefore, it can be recommended to improve and enhance such AI models in prediction of flow variables in critical zones and special hydraulic conditions using different evolutionary or optimization methods in combination with the classified models.

Open Access This article is distributed under the terms of the Creative Commons Attribution 4.0 International License (http://creativeco mmons.org/licenses/by/4.0/), which permits unrestricted use, distribution, and reproduction in any medium, provided you give appropriate credit to the original author(s) and the source, provide a link to the Creative Commons license, and indicate if changes were made.

\section{References}

Afan HA, El-shafie A, Mohtar WHMW, Yaseen ZM (2016) Past, present and prospect of an Artificial Intelligence (AI) based model for sediment transport prediction. J Hydrol 541:902-913

Ajmera TK, Goyal MK (2012) Development of stage-discharge rating curve using model tree and neural networks: an application to Peachtree Creek in Atlanta. Expert Syst Appl 39(5):5702-5710

Akhtari AA, Seyedashraf O (2017) Experimental and numerical investigation on vanes' effects on the flow characteristics in sharp $60^{\circ}$ bends. KSCE J Civ Eng 22:1-12

Akhtari AA, Abrishami J, Sharifi MB (2009) Experimental investigations of water surface characteristics in strongly-curved open channels. J Appl Sci 9(20):3699-3706

Al Sudani ZA, Salih SQ, Yaseen ZM (2019) Development of multivariate adaptive regression spline integrated with differential evolution model for streamflow simulation. J Hydrol 573:1-12

Al-Abadi AM (2016) Modeling of stage-discharge relationship for Gharraf River, southern Iraq using backpropagation artificial 
neural networks, M5 decision trees, and Takagi-Sugeno inference system technique: a comparative study. Appl Water Sci 6(4):407-420

Azamathulla HM, Ghani AA, Fei SY (2012) ANFIS-based approach for predicting sediment transport in clean sewer. Appl Soft Comput 12(3): 1227-1230

Balouchi B, Nikoo MR, Adamowski J (2015) Development of expert systems for the prediction of scour depth under live-bed conditions at river confluences: application of different types of ANNs and the M5P model tree. Appl Soft Comput 34:51-59

Basser H, Karami H, Shamshirband S, Jahangirzadeh A, Akib S, Saboohi H (2014) Predicting optimum parameters of a protective spur dike using soft computing methodologies-a comparative study. Comput Fluids 97:168-176

Bhattacharya B, Solomatine DP (2005) Neural networks and M5 model trees in modelling water level-discharge relationship. Neurocomputing 63:381-396

Bilhan O, Emiroglu ME, Kisi O (2011) Use of artificial neural networks for prediction of discharge coefficient of triangular labyrinth side weir in curved channels. Adv Eng Softw 42(4):208-214

Blanckaert K, Graf WH (2001) Mean flow and turbulence in openchannel bend. J Hydraul Eng 127(10):835-847

Bodnár T, Př́íhoda J (2006) Numerical simulation of turbulent free-surface flow in curved channel. Flow Turbul Combust 76(4):429-442

Bonakdari H, Gholami A (2016) Evaluation of artificial neural network model and statistical analysis relationships to predict the stable channel width. River Flow 2016: Iowa City, USA, July 11-14, 417

Bonakdari H, Zaji AH (2018) New type side weir discharge coefficient simulation using three novel hybrid adaptive neuro-fuzzy inference systems. Appl Water Sci 8(1):10

Broomhead DS, Lowe D (1988) Radial basis functions, multi-variable functional interpolation and adaptive networks (No. RSREMEMO-4148). Royal Signals and Radar Establishment Malvern (United Kingdom)

Chang FJ, Chang LC, Huang CW, Kao IF (2016) Prediction of monthly regional groundwater levels through hybrid soft-computing techniques. J Hydrol 541:965-976

Chen W, Fu ZJ, Chen CS (2014) Recent advances in radial basis function collocation methods. Springer, Berlin

Coppersmith D, Hong SJ, Hosking JR (1999) Partitioning nominal attributes in decision trees. Data Min Knowl Disc 3(2):197-217

De Marchis M, Napoli E (2006) 3D numerical simulation of curved open channel flows. WSEAS Trans Fluid Mech 1(2):175

De Vriend HJ, Geldof HJ (1983) Main flow velocity in short river bends. J Hydraul Eng 109(7):991-1011

Diop L, Bodian A, Djaman K, Yaseen ZM, Deo RC, El-Shafie A, Brown LC (2018) The influence of climatic inputs on stream-flow pattern forecasting: case study of Upper Senegal River. Environ Earth Sci 77(5):182

Ebtehaj I, Bonakdari H (2017) Design of a fuzzy differential evolution algorithm to predict non-deposition sediment transport. Appl Water Sci 7(8):4287-4299

Ferguson RI, Parsons DR, Lane SN, Hardy RJ (2003) Flow in meander bends with recirculation at the inner bank. Water Resour Res 39(11): 1322

Gan M, Peng H, Dong XP (2012) A hybrid algorithm to optimize RBF network architecture and parameters for nonlinear time series prediction. Appl Math Model 36(7):2911-2919

Gholami A, Akhtari AA, Minatour Y, Bonakdari H, Javadi AA (2014) Experimental and numerical study on velocity fields and water surface profile in a strongly-curved 90 open channel bend. Eng Appl Comput Fluid Mech 8(3):447-461

Gholami A, Bonakdari H, Zaji AH, Akhtari AA, Khodashenas SR (2015) Predicting the velocity field in a 90 open channel bend using a gene expression programming model. Flow Meas Instrum 46:189-192

Gholami A, Bonakdari H, Akhtari AA (2016a) Assessment of water depth change patterns in 120 sharp bend using numerical model. Water Sci Eng 9(4):336-344

Gholami A, Bonakdari H, Zaji AH, Ajeel Fenjan S, Akhtari AA (2016b) Design of modified structure multi-layer perceptron networks based on decision trees for the prediction of flow parameters in $90^{\circ}$ open-channel bends. Eng Appl Comput Fluid Mech 10(1):193-208

Gholami A, Bonakdari H, Zaji AH, Michelson DG, Akhtari AA (2016c) Improving the performance of multi-layer perceptron and radial basis function models with a decision tree model to predict flow variables in a sharp 90 bend. Appl Soft Comput 48:563-583

Gholami A, Bonakdari H, Akhtari AA (2016d) Developing finite volume method (FVM) in numerical simulation of flow pattern in $60^{\circ}$ open channel bend. J Appl Res Water Wastewater 3(1):193-200

Gholami A, Bonakdari H, Ebtehaj I, Shaghaghi S, Khoshbin F (2017a) Developing an expert group method of data handling system for predicting the geometry of a stable channel with a gravel bed. Earth Surf Proc Land 42(10):1460-1471

Gholami A, Bonakdari H, Ebtehaj I, Akhtari AA (2017b) Design of an adaptive neuro-fuzzy computing technique for predicting flow variables in a $90^{\circ}$ sharp bend. J Hydroinf 19(4):572-585

Gholami A, Bonakdari H, Zaji AH, Fenjan SA, Akhtari AA (2018a) New radial basis function network method based on decision trees to predict flow variables in a curved channel. Neural Comput Appl 30(9):2771-2785

Gholami A, Bonakdari H, Zeynoddin M, Ebtehaj I, Gharabaghi B, Khodashenas SR (2018b) Reliable method of determining stable threshold channel shape using experimental and gene expression programming techniques. Neural Comput Appl. https://doi. org/10.1007/s00521-018-3411-7

Gholami A, Bonakdari H, Ebtehaj I, Mohammadian M, Gharabaghi B, Khodashenas SR (2018c) Uncertainty analysis of intelligent model of hybrid genetic algorithm and particle swarm optimization with ANFIS to predict threshold bank profile shape based on digital laser approach sensing. Measurement 121:294-303

Gholami A, Bonakdari H, Ebtehaj I, Gharabaghi B, Khodashenas SR, Talesh SHA, Jamali A (2018d) A methodological approach of predicting threshold channel bank profile by multi-objective evolutionary optimization of ANFIS. Eng Geol 239:298-309

Gholami A, Bonakdari H, Mohammadian A (2019a) A method based on the Tsallis entropy for characterizing threshold channel bank profiles. Physica A 526:121089

Gholami A, Bonakdari H, Mohammadian M, Zaji AH, Gharabaghi B (2019b) Assessment of geomorphological bank evolution of the alluvial threshold rivers based on entropy concept parameters. Hydrol Sci J 64(7):856-872

Gholami A, Bonakdari H, Mohammadian M (2019c) Enhanced formulation of the probability principle based on maximum entropy to design the bank profile of channels in geomorphic threshold. Stoch Env Res Risk Assess 33:1-22

Gholami A, Bonakdari H, Akhtari AA, Ebtehaj I (2019d) A combination of computational fluid dynamics, artificial neural network and support vectors machines model to predict flow variables in curved channel. Scientia Iranica 26:726-741

Gholami A, Bonakdari H, Zaji AH, Akhtari AA (2019e) A comparison of artificial intelligence-based classification techniques in predicting flow variables in sharp curved channels. Eng Comput. https:// doi.org/10.1007/s00366-018-00697-7

Ghorbani MA, Khatibi R, Karimi V, Yaseen ZM, Zounemat-Kermani M (2018) Learning from multiple models using artificial intelligence to improve model prediction accuracies: application to river flows. Water Resour Manag 32(13):4201-4215

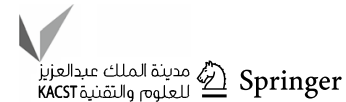


Ghosh A, Das P, Sinha K (2015) Modeling of biosorption of Cu (II) by alkali-modified spent tea leaves using response surface methodology (RSM) and artificial neural network (ANN). Appl Water Sci 5(2):191-199

Goyal MK, Ojha CSP (2011) Estimation of scour downstream of a ski-jump bucket using support vector and M5 model tree. Water Resour Manag 25(9):2177-2195

Jiang CLVJ, Ding Y, Lu W (2012) Hydropower project costs estimation based on the principal component analysis and RBF neural network. Agriculture Network Information 4:006

Jung JW, Yoon SE (2000) Flow and bed topography in a 180 curved channel. In 4th International conference on hydro-science and engineering, Korea Water Resources Association, Seoul, Korea

Kasiviswanathan KS, He J, Sudheer KP, Tay JH (2016) Potential application of wavelet neural network ensemble to forecast streamflow for flood management. J Hydrol 536:161-173

Khosravi K, Mao L, Kisi O, Yaseen ZM, Shahid S (2018) Quantifying hourly suspended sediment load using data mining models: case study of a glacierized Andean catchment in Chile. J Hydrol 567:165-179

Kim CM, Parnichkun M (2017) Prediction of settled water turbidity and optimal coagulant dosage in drinking water treatment plant using a hybrid model of $\mathrm{k}$-means clustering and adaptive neuro-fuzzy inference system. Appl Water Sci 7(7):3885-3902

Kisi O (2008) The potential of different ANN techniques in evapotranspiration modelling. Hydrol Process 22(14):2449-2460

Kisi O, Yaseen ZM (2019) The potential of hybrid evolutionary fuzzy intelligence model for suspended sediment concentration prediction. CATENA 174:11-23

Kisi O, Shiri J, Tombul M (2013) Modeling rainfall-runoff process using soft computing techniques. Comput Geosci 51:108-117

Kumar B, Jha A, Deshpande V, Sreenivasulu G (2014) Regression model for sediment transport problems using multi-gene symbolic genetic programming. Comput Electron Agric 103:82-90

Leschziner MA, Rodi W (1979) Calculation of strongly curved open channel flow. J Hydraul Div 105(10):1297-1314

Li Z, Yang Q, Wang L, Martín JD (2017) Application of RBFN network and GM $(1,1)$ for groundwater level simulation. Appl Water Sci 7(6):3345-3353

Li J, Salim RD, Aldlemy MS, Abdullah JM, Yaseen ZM (2019) Fiberglass-reinforced polyester composites fatigue prediction using novel data-intelligence model. Arab J Sci Eng 44(4):3343-3356

Lien HC, Hsieh TY, Yang JC, Yeh KC (1999) Bend flow simulation using 2D depth-averaged model. J Hydraul Eng ASCE 125(10):1097-1108

Lohani AK, Goel NK, Bhatia KKS (2014) Improving real time flood forecasting using fuzzy inference system. J Hydrol 509:25-41

Manu DS, Thalla AK (2017) Artificial intelligence models for predicting the performance of biological wastewater treatment plant in the removal of Kjeldahl Nitrogen from wastewater. Appl Water Sci 7(7):3783-3791

Moharana S, Khatua KK (2014) Prediction of roughness coefficient of a meandering open channel flow using Neuro-Fuzzy Inference System. Measurement 51:112-123

Moody J, Darken CJ (1989) Fast learning in networks of locallytuned processing units. Neural Comput 1(2):281-294

Naji MA, Ghodsian M, Vaghefi M, Panahpur N (2010) Experimental and numerical simulation of flow in a $90^{\circ}$ bend. Flow Meas Instrum 21(3):292-298

Park J, Sandberg IW (1991) Universal approximation using radialbasis-function networks. Neural Comput 3(2):246-257

Pektaş AO, Doğan E (2015) Prediction of bed load via suspended sediment load using soft computing methods. Geofizika $32: 27-46$
Ramamurthy AS, Han SS, Biron PM (2012) Three-dimensional simulation parameters for 90 open channel bend flows. J Comput Civ Eng 27(3):282-291

Sanikhani H, Deo RC, Samui P, Kisi O, Mert C, Mirabbasi R et al (2018) Survey of different data-intelligent modeling strategies for forecasting air temperature using geographic information as model predictors. Comput Electron Agric 152:242-260

Sarimveis H, Alexandridis A, Bafas G (2003) A fast training algorithm for RBF networks based on subtractive clustering. Neurocomputing 51:501-505

Senthil Kumar AR, Ojha CSP, Goyal MK, Singh RD, Swamee PK (2011) Modeling of suspended sediment concentration at Kasol in India using ANN, fuzzy logic, and decision tree algorithms. J Hydrol Eng 17(3):394-404

Shaheed R (2016) 3D Numerical Modelling of Secondary Current in Shallow River Bends and Confluences (Doctoral dissertation, Université d'Ottawa/University of Ottawa)

Solgi A, Zarei H, Nourani V, Bahmani R (2017) A new approach to flow simulation using hybrid models. Appl Water Sci 7(7):3691-3706

Solomatine DP, Dulal KN (2003) Model trees as an alternative to neural networks in rainfall-runoff modelling. Hydrol Sci J 48(3):399-411

Solomatine DP, Xue Y (2004) M5 model trees and neural networks: application to flood forecasting in the upper reach of the Huai River in China. J Hydrol Eng 9(6):491-501

Steffler PM, Rajaratnam N, Peterson AW (1985) Water surface at change of channel curvature. J Hydraul Eng 111(5):866-870

Sulaiman SO, Shiri J, Shiralizadeh H, Kisi O, Yaseen ZM (2018) Precipitation pattern modeling using cross-station perception: regional investigation. Environ Earth Sci 77(19):709

Tahershamsi A, Menhaj MB, Ahmadian R (2006) Sediment loads prediction using multilayer feedforward neural networks. Amirkabir 16(63):103-110

Tao H, Diop L, Bodian A, Djaman K, Ndiaye PM, Yaseen ZM (2018a) Reference evapotranspiration prediction using hybridized fuzzy model with firefly algorithm: regional case study in Burkina Faso. Agric Water Manag 208:140-151

Tao H, Sulaiman SO, Yaseen ZM, Asadi H, Meshram SG, Ghorbani MA (2018b) What is the potential of integrating phase space reconstruction with SVM-FFA data-intelligence model? Application of rainfall forecasting over regional scale. Water Resour Manag 32(12):3935-3959

Uddin MN, Rahman MM (2012) Flow and erosion at a bend in the braided Jamuna River. Int J Sedim Res 27(4):498-509

Wolfs V, Willems P (2014) Development of discharge-stage curves affected by hysteresis using time varying models, model trees and neural networks. Environ Model Softw 55:107-119

Wu X, Wang Y (2012) Extended and Unscented Kalman filtering based feedforward neural networks for time series prediction. Appl Math Model 36(3):1123-1131

Yaseen Z, Ehteram M, Sharafati A, Shahid S, Al-Ansari N, ElShafie A (2018a) The integration of nature-inspired algorithms with least square support vector regression models: application to modeling river dissolved oxygen concentration. Water 10(9): 1124

Yaseen ZM, Tran MT, Kim S, Bakhshpoori T, Deo RC (2018b) Shear strength prediction of steel fiber reinforced concrete beam using hybrid intelligence models: a new approach. Eng Struct 177:244-255

Ye J, McCorquodale JA (1998) Simulation of curved open channel flows by 3D hydrodynamic model. J Hydraul Eng 124(7):687-698

Yousif AA, Sulaiman SO, Diop L, Ehteram M, Shahid S, Al-Ansari N, Yaseen ZM (2019) Open channel sluice gate scouring 
parameters prediction: different scenarios of dimensional and non-dimensional input parameters. Water 11(2):353

Zahiri A, Azamathulla HM, Ghorbani K (2014) Prediction of local scour depth downstream of bed sills using soft computing models. In: Computational Intelligence Techniques in Earth and Environmental Sciences. Springer, Netherlands, pp 197-208

Zaji AH, Bonakdari H (2014) Performance evaluation of two different neural network and particle swarm optimization methods for prediction of discharge capacity of modified triangular side weirs. Flow Meas Instrum 40:149-156
Zaji AH, Bonakdari H, Shamshirband S, Qasem SN (2015) Potential of particle swarm optimization based radial basis function network to predict the discharge coefficient of a modified triangular side weir. Flow Meas Instrum 45:404-407

Publisher's Note Springer Nature remains neutral with regard to jurisdictional claims in published maps and institutional affiliations. 